\title{
28 Research Square

\section{Short-term renoprotective effect of SGLT-2 inhibitor for renal function and albuminuria in type 2 diabetes: a retrospective study}

Mitsunobu Kubota ( $\square$ takubonx@kba.biglobe.ne.jp )

National Hospital Organization Kure Medical Center and Chugoku Cancer Cenger

Eri Shiroyama

National Hospital Organization Kure Medical Center and Chugoku Cancer Center

Kanako Tanaka

National Hospital Organization Kure Medical Center and Chugoku Cancer Center

Yoko Yoshii

National Hospital Organization Kure Medical Center and Chugoku Cancer Center

\section{Research}

Keywords: SGLT-2 inhibitor, renoprotective effect, diabetic kidney disease, estimated glomerular filtration rate, albuminuria

Posted Date: June 17th, 2020

DOl: https://doi.org/10.21203/rs.3.rs-35892/v1

License: (c) (i) This work is licensed under a Creative Commons Attribution 4.0 International License. Read Full License

Version of Record: A version of this preprint was published at SN Comprehensive Clinical Medicine on January 1 st, 2021. See the published version at https://doi.org/10.1007/s42399-020-00707-0. 


\section{Abstract}

Background Progression of diabetic nephropathy in type 2 diabetic patients is a factor that determines the prognosis of life. Empagliflozin and canagliflozin, two oral diabetic SGLT-2 inhibitors, have shown improved renal outcomes in type 2 diabetic patients with chronic kidney disease in a large clinical study. These results suggest that SGLT-2 inhibitors could be used not only for hypoglycemic effects, but also for renal protective effects in patients with type 2 diabetes. It is not fully understood in which contexts the use of SGLT-2 inhibitors is likely to exert its renal protective effects. The purpose of this study was to clarify the profiles of patients in whom SGLT-2 inhibitors are more likely to exert a renal protective effect in clinical practice. We examined renal function and urinary albumin changes in short-term use of SGLT-2 inhibitors by patient background.

Methods We retrospectively analyzed the medical record information of sixty-three type 2 diabetic patients (33 males, 30 females, average age $53.0 \pm 13.0$ years) who were given usual doses of a SGLT-2 inhibitor. We investigated changes in body weight, blood pressure, glucose metabolism index, lipid metabolism index, estimated glomerular filtration rate (eGFR) and albuminuria (urinary albumin-tocreatinine ratio, UACR) three months before and after administration of a SGLT-2 inhibitor.

Results Three months after administration of an SGLT-2 inhibitor, there were improvements in glucose tolerance, weight loss, blood pressure, and lipid indices. In all cases, there was no significant change in eGFR, but UACR decreased significantly. UACR decreased regardless of Angiotensin II Receptor Blocker medication and significantly decreased in nephropathy patients with microalbuminuria or overt albuminuria. UACR decreased only in the group in which blood pressure, body weight, and hemoglobin A1c decreased before and after administration of the SGLT-2 inhibitor.

Conclusions Our study shows that the renoprotective effects of SGLT-2 inhibitors are more likely to be exerted in diabetic nephropathy patients who have advanced to at least microalbuminuria stage, and in addition to direct renal protection, the comprehensive effects of SGLT-2 inhibitors, which lower body weight, blood pressure, and blood glucose, are also important for their renal protection effects.

\section{Background}

Type 2 diabetes is an increasing trend worldwide [1]凶Although the long-term prognosis of patients with type 2 diabetes is improving, the mortality rate, especially mortality from cardiovascular disease, remains unsolved [2]. Sodium-glucose cotransporter 2 (SGLT-2) inhibitors are recently developed oral hypoglycemic drugs whose mechanism is mainly to inhibit glucose reabsorption from renal tubules via SGLT-2. It lowers blood glucose levels through urinary disposing. Unlike insulin or other oral hypoglycemic drugs that have insulin secretion effect, SGLT-2 inhibitors have been reported to have other beneficial effects, such as body weight loss and reduction of blood pressure, while maintaining a low risk of hypoglycemia [3]. In addition, SGLT-2 inhibitors are reported to have cardio-protective effects in patients with type 2 diabetes, not only in Western countries [4,5], but in Asian countries as well [6]. Renal function 
and urinary albumin excretion rate are associated with cardiovascular death [7], and renal complications need to be considered when considering the risk of cardiovascular disease (CVD) for type 2 diabetes. Recently, a SGLT-2 inhibitor, canagliflozin, was reported to reduce the relative risk of primary endpoints by $30 \%$, such as progression to end-stage renal failure, doubling of serum creatinine (Cre) levels, and death due to renal disease in patients with type 2 diabetes with chronic kidney disease (CKD) [8]. This is the first large-scale clinical trial with renal outcomes due to SGLT-2 inhibitors as the primary endpoint. This study addresses the growing need to focus on the renal protective effects of SGLT-2 inhibitors in diabetic patients.

Diabetic nephropathy is a diabetic microvascular complication. Nephropathy progresses to microalbuminuria, overt albuminuria, and decreased renal function, and is associated with increased mortality [9]. The prevalence of diabetic nephropathy in type 2 diabetes is reported as the proportion with microalbuminuria or overt albuminuria, which is $30-40 \%$ in Europe and the United States [10] and 7-20\% in Asian countries [11]. In Japan, the prevalence of diabetic nephropathy in type 2 diabetic patients is reported as high as $42 \%$ [12]. Since renal replacement therapy such as hemodialysis or peritoneal dialysis impairs patient quality of life, the development of a therapy to prevent the development of chronic renal failure in type 2 diabetic patients is desired. At present, treatment of diabetic nephropathy mainly consists of treatment for glomerular hypertension by diet, glycemic control, treatment of hypertension, especially suppression of the renin-angiotensin system (RAS), and treatment for dyslipidemia [13]. Clinical studies examining the effectiveness of strict glycemic control, such as ACCORD [14], ADVANCE [15], and the Kumamoto study [16], showed that strict glycemic control could significantly suppress a new onset of microalbuminuria and progression to overt albuminuriaDThese results suggest that strict glycemic control may be effective for the early stage of nephropathy. At the same time, however, the effectiveness of strict glycemic control was not observed in kidney-related hard endpoints such as serum creatinine doubling, progression to end-stage renal failure, and kidney-related death [17]. In 2015, the SGLT-2 inhibitor empagliflozin reduced the deaths of diabetic patients at high risk of cardiovascular events by $40 \%$ [4], and also reduced the incidence and worsening rate of nephropathy by $38 \%$, the doubling of serum creatinine by $44 \%$, and the introduction of dialysis by $55 \%$ [18]. Of note, more than $80 \%$ of the study participants had already taken RAS inhibitors. RAS inhibitors had already been reported as improving renal-related hard endpoints, such as promoting resolution of urinary albumin in early nephropathy and suppressing renal function decline in cases of overt nephropathy [19-22]. Similar results indicate that the CANVAS program, which administered canagliflozin to patients with type 2 diabetes at high risk for cardiovascular events, also reduced the development of albuminuria by $27 \%$, and showed that the renal complex endpoint (decreased estimated glomerular filtration rate (GFR), initiation of renal replacement therapy, and death from renal disease) were significantly reduced by $40 \%$ [5]. These results suggest that SGLT-2 inhibitors may be an oral hypoglycemic drug with a different mechanism from that of RAS inhibitors in inhibiting the progression of diabetic nephropathy. Accordingly, it is important for clinicians to examine the background of patients in whom the renal protective effect of SGLT-2 inhibitors is likely to be exerted. 
Previous large-scale clinical studies suggest that SGLT-2 inhibitors could be used as a drug with not only a hypoglycemic effect but also a renal protective effect in patients with type 2 diabetes. However, it is not fully understood in what background a SGLT-2 inhibitor is more likely to exert its effects. Therefore, we investigated changes in renal function and urinary albumin in the short-term use of SGLT-2 inhibitors, focusing on patient background before administration, especially changes in body weight, blood pressure, and blood glucose. The purpose of this study was to clarify in which patients the renal protective effect of SGLT-2 inhibitors at a usual dose in Japan is likely to be demonstrated in actual clinical settings.

\section{Methods}

\section{Study_group}

Of the outpatients with type 2 diabetes who visited our department from April 2017 to March 2018, 98 patients who started a Japanese standard dose of SGLT-2 inhibitor were extracted from the medical record. We excluded twenty-two patients who had changed their diabetes drugs, nine patients who had stopped taking SGLT-2 inhibitors due to side effects such as urinary frequency, urinary tract infection, skin eruption, and four patients who did not have follow-up due to transfer to another hospital. The remaining 63 people were included in this analysis. Sixty-three type 2 diabetic patients were 33 males, 30 females, and mean age $53.0 \pm 13.0$ years old. The SGLT-2 inhibitors were: Empagliflozin $10 \mathrm{mg}$ in 20 patients, Canagliflozin $100 \mathrm{mg}$ in 20 patients, Dapagliflozin $10 \mathrm{mg}$ in 11 patients, Tofogliflozin $20 \mathrm{mg}$ in 9 patients, and Ipragliflozin $50 \mathrm{mg}$ in 3 patients (Table 1). We examined changes in body weight, blood pressure, glucose metabolism indices, lipid metabolism indices, and indicators related to diabetic nephropathy, estimated glomerular filtration rate (eGFR, as calculated by the Chronic Kidney Disease Epidemiology Collaboration formula [23]) and albuminuria (urinary albumin-to-creatinine ratio, UACR, with albumin measured in milligrams and creatinine in grams), as measured in a laboratory. No changes were made in diabetes or lipid treatment between the three months before and after administration of SGLT-2 inhibitors. The average for 3 months before and after the change of SGLT-2 inhibitor was $90.0 \pm 3.9$ (Mean \pm standard deviation) days. Each participant was interviewed and provided informed consent. This study was approved by the Ethics Committee of National Hospital Organization of Kure Medical Center.

\section{Biochemical analyses}

After overnight fasting, each participant underwent a physical examination and venous blood collection. Body measurements were taken in the standing position. Body mass index (BMI) was calculated as weight $(\mathrm{kg}) /$ height $(\mathrm{m})^{2}$. Collected blood and urine samples were centrifuged and measured by each method. Plasma glucose levels were measured by the glucose oxidase method. Hemoglobin A1c (HbA1c) levels were measured by high-performance liquid chromatography (HPLC) with an HLC723-G9 instrument (Tosoh, Tokyo, Japan). Serum and urine creatinine levels were measured by the oxidase method (Mizuho 
Medy, Tokyo, Japan). eGFR (mL/min/1.73 $\left.\mathrm{m}^{2}\right)$ was calculated as: 194 x Serum creatinine (-1.094) x Age $(-0.287) \times 0.739$ (if female) [23]. Serum total cholesterol (TC) and triglyceride (TG) levels were assessed by an enzymatic method. High-density lipoprotein cholesterol (HDL-C) level was measured directly by homogenous assay. Low-density-lipoprotein cholesterol (LDL-C) was calculated by the Friedewald equation [24]. Urine albumin quantification was measured using the immunoturbidimetry method (Nittobo Medical, Tokyo, Japan).

\section{$\underline{\text { Statistical Analysis }}$}

The data are expressed as the mean \pm S.E or median $\left(25^{\text {th }}-75^{\text {th }}\right.$ percentile), depending on the data distribution. Because of the skewed distribution of data, TG, eGFR and UACR values was logarithmically transformed and analyzed. The differences in continuous variables were analyzed using Student's $t$-test. A paired t-test was used to test the significant difference in parameter changes before and after SGLT-2 inhibitor administration. Categorical variables were analyzed using the $c^{2}$ test. $P$ values $<0.05$ were considered statistically significant. All analyses were performed using the software package SPSS version 20 (IBM Co. Ltd., Armonk, NY, USA).

\section{Results}

Table 1 shows the patient background of each subject before SGLT-2 inhibitor administration. The average age was $53.0 \pm 2.0$ years old, BMI was $29.9 \pm 7.9 \mathrm{~kg} / \mathrm{m}^{2}$, and overweight. Mean fasting blood glucose level was $208.4 \pm 11.0 \mathrm{mg} / \mathrm{dL}$ and $\mathrm{HbA} 1 \mathrm{c}$ was $9.4 \pm 0.2 \%$, indicating poor blood glucose control. The eGFR of the baseline was 85 (73-103) $\mathrm{ml} / \mathrm{min} / 1.73 \mathrm{~m}^{2}$ and UACR was $43(13-252) \mathrm{mg} / \mathrm{gCre}$. From the view point of the classification of Diabetic Nephropathy 2014: A Report from Joint Committee on Diabetic Nephropathy Classification [25], the number of stage 1 (normoalbuminuria $<30 \mathrm{mg} / \mathrm{gCr}$ and eGFR $\geqq 30 \mathrm{ml} / \mathrm{min} / 1.73 \mathrm{~m}^{2}$ ) was 29 , stage 2 (microalbuminuria $30-299 \mathrm{mg} / \mathrm{gCre}$ and eGFR $\geqq$ $30 \mathrm{ml} / \mathrm{min} / 1.73 \mathrm{~m}^{2}$ ) was 21 , and stage 3 (overt albuminuria $\geqq 300 \mathrm{mg} / \mathrm{gCr}$ and eGFR $\geqq$ $30 \mathrm{ml} / \mathrm{min} / 1.73 \mathrm{~m}^{2}$ ) was 13 . No patients were in stage 4 (eGFR $\left.<30 \mathrm{ml} / \mathrm{min} / 1.73 \mathrm{~m} 2\right)$ and stage 5 (during dialysis therapy). Twenty-eight of 63 patients were under treatment with a usual dose of Angiotensin II Receptor Blocker (ARB).

There was improving glucose tolerance, such as fasting plasma glucose and $\mathrm{HbA} 1 \mathrm{c}$ level, three months after new administration of SGLT-2 inhibitors as shown in Fig. 1a. Improvements in body weight $(2.1 \mathrm{~kg})$ and blood pressure $(6 \mathrm{mmHg})$ are shown in Fig. 1b. Lipid parameters also improved (Total cholesterol $9.8 \mathrm{mg} / \mathrm{dL}$, and nonHDL-C $10.2 \mathrm{mg} / \mathrm{dL}$, Fig. 1c).

Data related to nephropathy are shown in Fig. 2. In all cases, eGFR did not change significantly from 85 $(73-103) \mathrm{mL} / \mathrm{min} / 1.73 \mathrm{~m}^{2}$ to $83(68-99) \mathrm{mL} / \mathrm{min} / 1.73 \mathrm{~m}^{2}$ after three months administration of the 
usual dose of SGLT-2 inhibitors $(P=0.165)$. However, UACR level decreased significantly from $43(13-$ $252) \mathrm{mg} / \mathrm{gCre}$ to $26(11-143) \mathrm{mg} / \mathrm{gCre}(P<0.001)$.

Next, to examine the effect of ARB administration at baseline on the renal protective effect of SGLT-2 inhibitors, changes in GFR and UCAR levels were analyzed according to the presence or absence of ARB oral administration. In the 28 patients with ARB oral administration, eGFR was significantly decreased 90 (76-110) $\mathrm{mL} / \mathrm{min} / 1.73 \mathrm{~m}^{2}$ to $87(76-111) \mathrm{mL} / \mathrm{min} / 1.73 \mathrm{~m}^{2}(P=0.044)$, and the UACR level was also significantly decreased 26 (10-244) mg/gCre to 18 (8-150) mg/gCre $(P<0.001)$ (Fig. 2.a). The other 35 patients without ARB oral administration, eGFR was similarly decreased from 84 (71-113) $\mathrm{mL} / \mathrm{min} / 1.73 \mathrm{~m}^{2}$ to $82(62-108) \mathrm{mL} / \mathrm{min} / 1.73 \mathrm{~m}^{2}(P=0.045)$, UACR significantly decreased from 66 (13-429) $\mathrm{mg} / \mathrm{g}$ Cre to $29(18-199) \mathrm{mg} / \mathrm{gCre}(P=0.002)$ (Fig. 2.b).

Subsequently, the effects of SGLT-2 inhibitors were compared by diabetic nephropathy staging at baseline (Table 2). Body weight and glucose metabolism indices were significantly decreased in all three groups from normoalbuminuria to overt albuminuria. Systolic blood pressure was significantly decreased only in the normoalbuminuria group. GFR did not change significantly in all three groups. UACR levels were significantly reduced only in the microalbuminuria and overt albuminuria groups.

Finally, urinary albumin excretion is expected to be affected by changes in blood pressure, body weight, and glycemic control. Therefore, we analyzed changes in GFR and UACR according to subgroups with decreased systolic blood pressure $(n=39)$ or without $(n=24)$, subgroups with decreased body weight $(n=$ 49 ) or without $(n=14)$, and subgroups with improved HbA1c levels $(n=56)$ or not $(n=7)$, before and after administration of SGLT-2 inhibitors (Table 3). As a result, UACR level was significantly decreased only in the group in which systolic blood pressure, body weight, and HbA1c level were improved. eGFR did not change significantly in all groups.

\section{Discussion}

The new administration of SGLT-2 inhibitors improved glycemic control, and also reduced body weight, blood pressure, and urinary albumin in the short term. In this study, we found that a decrease in UACR levels was observed in nephropathy patients with micro or overt albuminuria, especially in the group with decreased body weight, blood pressure, and blood glucose, regardless of oral administration of RAS inhibitors. This study shows that SGLT-2 inhibitors have a renal protective effect independent of RAS inhibitors, and in addition to the direct renal protective effects of SGLT-2 inhibitors, the comprehensive actions of SGLT-2 inhibitors, which improved body weight, blood pressure, and blood glucose, were also important for the renal protective effect.

SGLT-2 inhibitors are shown to have renal protective effects by directly lowering glomerular pressure, correcting glomerular hyperfiltration, and suppressing excessive glucose reabsorption by tubular cells [26-28]. In addition, inhibition of SGLT-2 reduces Glucose/ $\mathrm{Na}+$ reabsorption in proximal tubules and increases and regulates $\mathrm{Na}+$ reaching tubule macrodensers, thereby correcting glomerular hyperfiltration, 
which has been reported to suppress nephropathy progression [29]. Meanwhile, it has been reported that hypertension increases proteinuria and albuminuria and causes a decrease in renal function due to glomerular load [30]. Obesity-related nephropathy has been also reported as an effect of obesity on the kidneys, resulting in increased glomerular filtration rate, increased renal blood flow, and renal swelling, and proteinuria [31]. In other words, the renal protective effects of SGLT-2 inhibitors may contribute not only to the direct effects on glomeruli, but also to comprehensive renal protective effects via weight loss, and a lowering of blood pressure and blood glucose. Increased urinary albumin is a predictor of the progression of diabetic nephropathy [9], and decreased urinary albumin has been reported to reduce the risk of end-stage renal failure and CVD [32].

Our study found a urinary albumin-improving effect from SGLT-2 inhibitors, especially in patients with microalbuminuria and overt albuminuria (Table 2), and these effects are independent of RAS inhibitors (Fig. 2a, b). There is a possibility that SGLT-2 inhibitors could be used in the future as an approved renoprotective medication in type 2 diabetes alongside ARB.

In this study, eGFR tended to decrease in the short term of 3 months after SGLT-2 inhibitor administration (Fig. 2). This is consistent with the fact that the canagliflozin group showed a greater decrease in eGFR in the early 12 months after the start of the study compared to the placebo group. In the CREDENCE trial, subsequent changes were slow, reversed from the placebo group after 12 months, and the long-term eGFR decline reduction effect was observed in the canagliflozin group [8]. SGLT-2 inhibitors have an effect on improving glomerular hyperfiltration in diabetic nephropathy and this may be a possible mechanism for the short-term decline of GFR after administration of an SGLT-2 inhibitor.

\section{Study limitations}

There are some limitations in this research. First, this was an observational study. Indeed, prospective studies are needed to determine whether SGLT-2 inhibitors can improve renal function. Second, we targeted people who took multiple SGLT-2 inhibitors. The purpose of this study was to evaluate the usefulness of SGLT-2 inhibitors as a class effect, but we did not examine whether the effect differs depending on the type of single drug. Third, the subjects in this study had relatively good renal function (eGFR $\geqq 30 \mathrm{ml} / \mathrm{min} / 1.73 \mathrm{~m}^{2}$ ). Further discussion is needed on renal protection in patients with more severe renal failure.

\section{Conclusions}

This study suggests that SGLT-2 inhibitors have a short-term effect on decreasing urinary albumin excretion, especially in diabetic nephropathy patients who have advanced to at least microalbuminuria stage, and especially in subjects with improved blood pressure, weight, and blood glucose levels. This is an important clinical finding that clarifies patients who are likely to exert the renal protective effects of SGLT-2 inhibitors. 


\section{List Of Abbreviations}

SGLT-2, Sodium-glucose cotransporter 2; eGFR, estimated glomerular filtration rate; UACR, urinary albumin-to-creatinine ratio; RAS, renin-angiotensin system; CVD, cardiovascular disease; Cre, creatinine; CKD, chronic kidney disease; BMI, body mass indes; HbA1c, Hemoglobin A1c; TC, total cholesterol; TG, triglyceride; HDL-C, high-density lipoprotein cholesterol; LDL-C, low-density lipoprotein cholesterol; ARB, Angiotensin II Receptor Blocker.

\section{Declarations}

\section{Ethics approval and consent to participate}

The study protocols were approved by the Ethics Committee of National Hospital Organization of Kure Medical Center, and informed consent was provided by all subjects.

\section{Consent for publication}

Not applicable

\section{Availability of data and material}

The datasets used/or analysed during the current study available from the corresponding author on reasonable request.

\section{Competing interests}

The authors declare that there are no conflicts of interest.

\section{Funding}

This research was supported in part by Kure medical center's academia-industry collaboration policy position the collaboration between Kure medical center and Kyowa Kirin Co., Ltd.

\section{Authors' contributions}


M.K. collected, analyzed and interpreted the data, and wrote the manuscript. R.S. reviewed the manuscript. K.T. collected the data and reviewed the manuscript. Y.Y. reviewed the manuscript. All authors read and approved the final version of the manuscript.

\section{Acknowledgments}

Not applicable

\section{References}

1. Guariguata L, Whiting DR, Hambleton I, Beagley J, Linnenkamp U, Shaw JE. Global estimates of diabetes prevalence for 2013 and projections for 2035. Diabetes Res Clin Pract. 2014;103:137-49.

2. Rawshani A, Rawshani A, Franzén S, Eliasson B, Svensson AM, Miftaraj M, McGuire DK, Sattar N, Rosengren A, Gudbjörnsdottir S. Mortality and Cardiovascular Disease in Type 1 and Type 2 Diabetes. N Engl J Med. 2017;13:376:1407-1418.

3. Riser Taylor S, Harris KB. The clinical efficacy and safety of sodium glucose cotransporter-2 inhibitors in adults with type 2 diabetes mellitus. Pharmacotherapy. 2013;33:984-99.

4. Zinman B, Wanner C, Lachin JM, Fitchett D, Bluhmki E, Hantel S, Mattheus M, Devins T, Johansen OE, Woerle HJ, Broedl UC, Inzucchi SE. EMPA-REG OUTCOME Investigators. Empagliflozin, Cardiovascular Outcomes, and Mortality in Type 2 Diabetes. N Engl J Med. 2015;26:373:2117-28.

5. Neal B, Perkovic V, Mahaffey KW, de Zeeuw D, Fulcher G, Erondu N, Shaw W, Law G, Desai M, Matthews DR, CANVAS Program Collaborative Group. Canagliflozin and Cardiovascular and Renal Events in Type 2 Diabetes. N Engl J Med. 2017;17:377:644-57.

6. Kaku K, Lee J, Mattheus M, Kaspers S, George J, Woerle HJ. EMPA-REG OUTCOME® Investigators. Empagliflozin and Cardiovascular Outcomes in Asian Patients With Type 2 Diabetes and Established Cardiovascular Disease - Results From EMPA-REG OUTCOME®. Circ J. 2017;25:81:227-34.

7. Gerstein HC, Mann JF, Yi Q, Zinman B, Dinneen SF, Hoogwerf B, Hallé JP, Young J, Rashkow A, Joyce C, Nawaz S, Yusuf S, HOPE Study Investigators. Albuminuria and risk of cardiovascular events, death, and heart failure in diabetic and nondiabetic individuals. JAMA. 2001;25:286:421-6.

8. Perkovic V, Jardine MJ, Neal B, Bompoint S, Heerspink HJL, Charytan DM, Edwards R, Agarwal R, Bakris G, Bull S, Cannon CP, Capuano G, Chu PL, de Zeeuw D, Greene T, Levin A, Pollock C, Wheeler DC, Yavin Y, Zhang H, Zinman B, Meininger G, Brenner BM, Mahaffey KW. CREDENCE Trial Investigators. Canagliflozin and Renal Outcomes in Type 2 Diabetes and Nephropathy. N Engl J Med. 2019;13:380:2295-306.

9. Adler Al, Stevens RJ, Manley SE, Bilous RW, Cull CA, Holman RR, UKPDS GROUP. Development and progression of nephropathy in type 2 diabetes: the United Kingdom Prospective Diabetes Study (UKPDS 64). Kidney Int. 2003;63:225-32. 
10. Parving HH, Lewis JB, Ravid M, Remuzzi G, Hunsicker LG. DEMAND investigators. Prevalence and risk factors for microalbuminuria in a referred cohort of type II diabetic patients: a global perspective. Kidney Int. 2006;69:2057-63.

11. Wu AY, Kong NC, de Leon FA, Pan CY, Tai TY, Yeung VT, Yoo SJ, Rouillon A, Weir MR. An alarmingly high prevalence of diabetic nephropathy in Asian type 2 diabetic patients: the MicroAlbuminuria Prevalence (MAP) Study. Diabetologia. 2005;48:17-26.

12. Yokoyama H, Kawai K, Kobayashi M, Japan Diabetes Clinical Data Management Study Group. Microalbuminuria is common in Japanese type 2 diabetic patients: a nationwide survey from the Japan Diabetes Clinical Data Management Study Group (JDDM 10). Diabetes Care. 2007;30:98992.

13. Roscioni SS, Heerspink HJ, de Zeeuw D. The effect of RAAS blockade on the progression of diabetic nephropathy. Nat Rev Nephrol. 2014;10:77-87.

14. Bonds DE, Miller ME, Bergenstal RM, Buse JB, Byington RP, Cutler JA, Dudl RJ, Ismail-Beigi F, Kimel AR, Hoogwerf $B$, et al. The association between symptomatic, severe hypoglycaemia and mortality in type 2 diabetes: retrospective epidemiological analysis of the ACCORD study. BMJ. 2010;340:b4909.

15. ADVANCE Collaborative Group. MacMahon S, Chalmers J, Neal B, Billot L, Woodward M, Marre M, Cooper M, Glasziou P, et al. Intensive blood glucose control and vascular outcomes in patients with type 2 diabetes. N Engl J Med 2008;358: 2560-72.

16. Shichiri M, Kishikawa H, Ohkubo Y, Wake N. Long-term results of the Kumamoto Study on optimal diabetes control in type 2 diabetic patients. Diabetes Care. 2000;23:B21-9.

17. Coca SG, Ismail-Beigi F, Haq N, Krumholz HM, Parikh CR. Role of intensive glucose control in development of renal end points in type 2 diabetes mellitus: systematic review and meta-analysis intensive glucose control in type 2 diabetes. Arch Intern Med. 2012;172:761-9.

18. Wanner C, Inzucchi SE, Lachin JM, Fitchett D, von Eynatten M, Mattheus M, Johansen OE, Woerle HJ, Broedl UC, Zinman B. EMPA-REG OUTCOME Investigators. Empagliflozin and Progression of Kidney Disease in Type 2 Diabetes. N Engl J Med. 2016;375:323-34.

19. Parving HH, Lehnert H, Bröchner-Mortensen J, Gomis R, Andersen S, Arner P. Irbesartan in Patients with Type 2 Diabetes and Microalbuminuria Study Group. The effect of irbesartan on the development of diabetic nephropathy in patients with type 2 diabetes. N Engl J Med. 2001;345:8708.

20. Makino H, Haneda M, Babazono T, Moriya T, Ito S, Iwamoto Y, Kawamori R, Takeuchi M, Katayama S, INNOVATION Study Group. Diabetes Care. 2007;30:1577-8.

21. Brenner BM, Cooper ME, de Zeeuw D, Keane WF, Mitch WE, Parving HH, Remuzzi G, Snapinn SM, Zhang Z, Shahinfar S. RENAAL Study Investigators. Effects of losartan on renal and cardiovascular outcomes in patients with type 2 diabetes and nephropathy. N Engl J Med. 2001;345:861-9.

22. Lewis EJ, Hunsicker LG, Clarke WR, Berl T, Pohl MA, Lewis JB, Ritz E, Atkins RC, Rohde R, Raz I. Collaborative Study Group. Renoprotective effect of the angiotensin-receptor antagonist irbesartan in patients with nephropathy due to type 2 diabetes. N Engl J Med. 2001;345:851-60. 
23. Matsuo S, Imai E, Horio M, Yasuda Y, Tomita K, Nitta K, Yamagata K, Tomino Y, Yokoyama H, Hishida A. Collaborators developing the Japanese equation for estimated GFR. Revised equations for estimated GFR from serum creatinine in Japan. Am J Kidney Dis. 2009;53:982-92.

24. Friedewald WT, Levy RI, Fredrickson DS. Estimation of the concentration of low-density lipoprotein cholesterol in plasma, without use of the preparative ultracentrifuge. Clin Chem. 1972;18:499-502.

25. Masakazu Haneda K, Utsunomiya D, Koya T, Babazono T, Moriya H, Makino K, Kimura Y, Suzuki T, Wada S, Ogawa M, Inaba Y, Kanno T, Shigematsu I, Masakane. Ken Tsuchiya, Keiko Honda, Kazuko Ichikawa, Kenichiro Shide, and Joint Committee on Diabetic Nephropathy. A new Classification of Diabetic Nephropathy 2014: a report from Joint Committee on Diabetic Nephropathy. J Diabetes Investig. 2015;6:242-6.

26. Ortola FV, Ballermann BJ, Anderson S, Mendez RE, Brenner BM. Elevated plasma atrial natriuretic peptide levels in diabetic rats. Potential mediator of hyperfiltration. J Clin Invest. 1987;80:670-4.

27. Brenner BM, Ballermann BJ, Gunning ME, Zeidel ML. Diverse biological actions of atrial natriuretic peptide. Physiol Rev. 1990;70:665-99.

28. Sternlicht H, Bakris GL. Blood Pressure Lowering and Sodium-Glucose Co-transporter 2 Inhibitors (SGLT2is): More Than Osmotic Diuresis. Curr Hypertens Rep. 2019;21:12.

29. Esterline RL, Vaag A, Oscarsson J, Vora J. MECHANISMS IN ENDOCRINOLOGY: SGLT2 inhibitors: clinical benefits by restoration of normal diurnal metabolism? Eur J Endocrinol. 2018;178:113-25.

30. Rossing K, Christensen PK, Hovind P, Parving HH. Remission of nephrotic-range albuminuria reduces risk of endī 14 \stage renal disease and improves survival in type 2 diabetic patients. Diabetologia. 2005;48:2241-47.

31. Weisinger JR, Kempson RL, Eldridge FL, Swenson RS. The nephrotic syndrome: a complication of massive obesity. Ann Intern Med. 1974;81:440-7.

32. Araki S, Haneda M, Koya D, Hidaka H, Sugimoto T, Isono M, Isshiki K, Chin-Kanasaki M, Uzu T, Kashiwagi A. Reduction in microalbuminuria as an integrated indicator for renal and cardiovascular risk reduction in patient with type 2 diabetes. Diabetes. 2007;56:1727-30.

\section{Table 1}

\section{Table 1-Baseline participant characteristics}




\begin{tabular}{|c|c|}
\hline$\overline{\mathrm{N} \text { (Men/Women) }}$ & $63(33 / 30)$ \\
\hline Age, years & $53.0 \pm 13.0$ \\
\hline Height, $\mathrm{cm}$ & $162.2 \pm 1.3$ \\
\hline Body weight, $\mathrm{kg}$ & $78.1 \pm 2.2$ \\
\hline BMI, $k g / m^{2}$ & $29.9 \pm 7.9$ \\
\hline Systolic BP, $\mathrm{mmHg}$ & $139 \pm 2$ \\
\hline Diastolic BP, $\mathrm{mmHg}$ & $81 \pm 2$ \\
\hline Fasting glucose, $m g / d l$ & $208.4 \pm 11.0$ \\
\hline HbA1c, \% & $9.4 \pm 0.2$ \\
\hline $\mathrm{TC} \square m g / d l$ & $197.5 \pm 5.9$ \\
\hline $\mathrm{LDL}-\mathrm{C}, \mathrm{mg} / \mathrm{dl}$ & $112.8 \pm 4.7$ \\
\hline HDL-C, $m g / d l$ & $49.0 \pm 1.5$ \\
\hline $\mathrm{TG}, m g / d l$ & $213 \pm 24$ \\
\hline Non HDL-C, $m g / d l$ & $148.6 \pm 5.7$ \\
\hline Estimated GFR, $\mathrm{ml} / \mathrm{min} / 1.73 \mathrm{~m}^{2}$ & $85(73-103)$ \\
\hline Urinary albumin-to-creatinine ratio-mg/gCre & $43(13-252)$ \\
\hline $\begin{array}{l}\text { Urinary albumin-to-creatinine ratio-no. } \\
<30 / 30 \text { to } 300 />300\end{array}$ & $29 / 21 / 13$ \\
\hline \multicolumn{2}{|l|}{ Concomitant medication- no.(\%) } \\
\hline Usual dose SGLT2 inhibitors & \\
\hline Empagliflozin 10mg & $20(31.7)$ \\
\hline Canagliflozin 100mg & $20(31.7)$ \\
\hline Dapagliflozin $10 \mathrm{mg}$ & $11(17.5)$ \\
\hline Tofogliflozin 20mg & $9(14.3)$ \\
\hline Ipragliflozin 50mg & $3(4.8)$ \\
\hline Angiotensin II receptor blocker & $28(44.4)$ \\
\hline Statin & $31(49.2)$ \\
\hline DPP-4 inhibitor & $48(76.2)$ \\
\hline Metformin & $27(42.9)$ \\
\hline Suøfonylurea & $10(15.9)$ \\
\hline$\alpha$-Glucosidase inhibitor & $5(7.9)$ \\
\hline Pioglitazone & $2(3.2)$ \\
\hline
\end{tabular}

BMI, body mass index; $\mathrm{BP}$, blood pressure; HbA1c, hemoglobin A1c; TC, total cholesterol;

LDL, low-density lipoprotein; HDL, high-density lipoprotein; TG, triglyceride; SGLT-2, Sodium-glucose cotransporter 2; GFR, glomerular filtration rate; DPP-4, dipeptidyl peptidase 4.

Data are presented as number, mean \pm S.E. or median $\left(25^{\text {th }}-75^{\text {th }}\right.$ percentile levels $)$. 
[Please see the supplementary files section to view the other tables.]

\section{Figures}
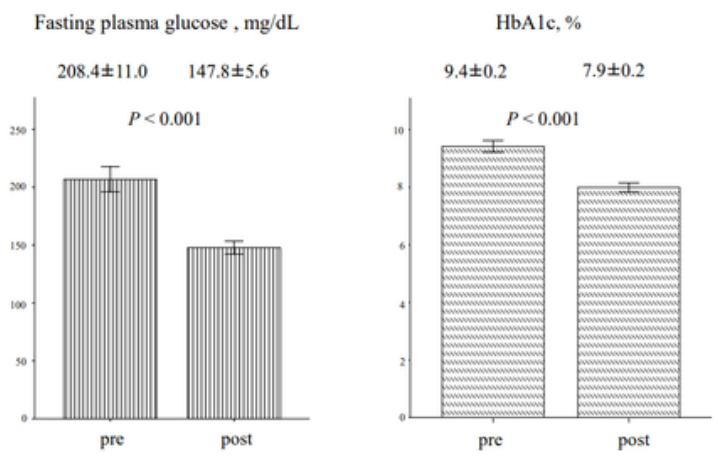

Body weight, $\mathrm{kg}$

Systolic BP, mmHg

Diastolic BP, mmHg
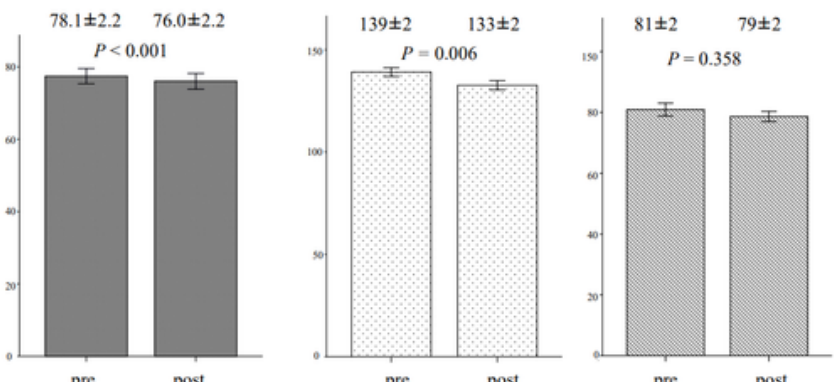

pre

post

pre post
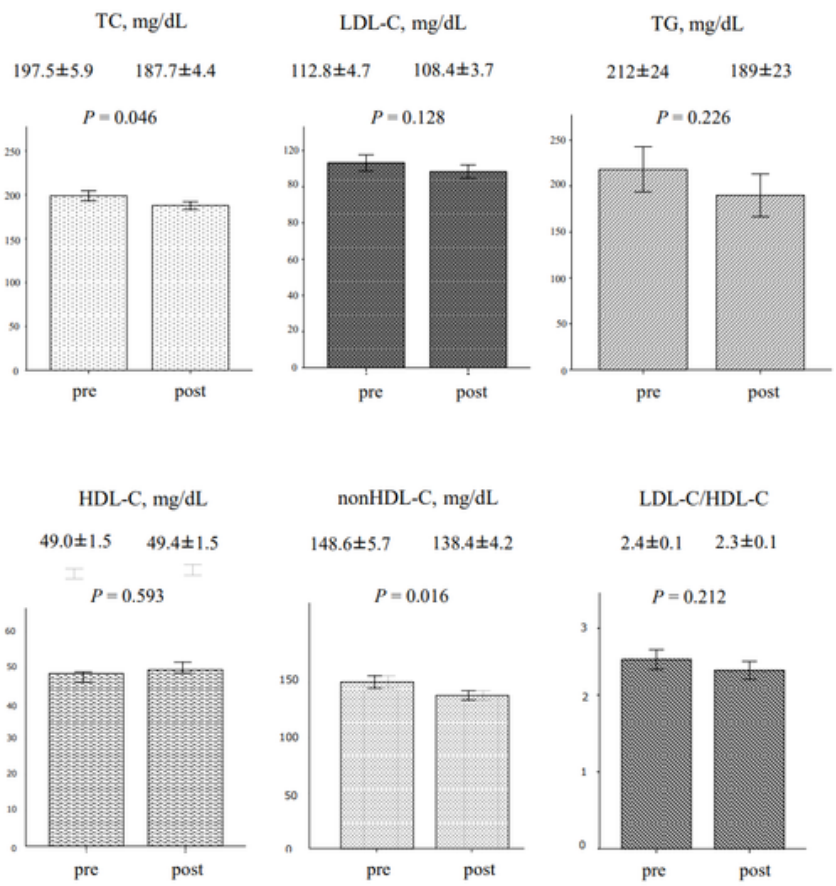

LDL-C/HDL-C

$2.4 \pm 0.1 \quad 2.3 \pm 0.1$

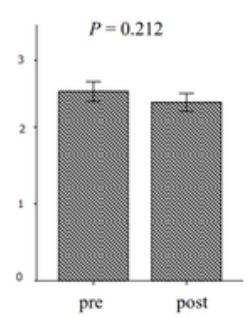




\section{Figure 1}

1a-Changes in glucose metabolism indices before and 3 months after administration of usual dose of SGLT-2 inhibitors. Values are shown as mean \pm S.E. HbA1c, Hemoglobin A1c. 1b-Changes in body weight and blood pressures before and 3 months after administration of usual dose of SGLT-2 inhibitors. Values are shown as mean \pm S.E. BP, blood pressure. $1 \mathrm{c}-$ Changes in lipid metabolism indices before and 3 months after administration of usual dose of SGLT-2 inhibitors. Values are shown as mean \pm S.E. TC, total cholesterol, LDL-C, low density-lipoprotein cholesterol, TG, triglyceride, HDL-C, high density-lipoprotein cholesterol. 


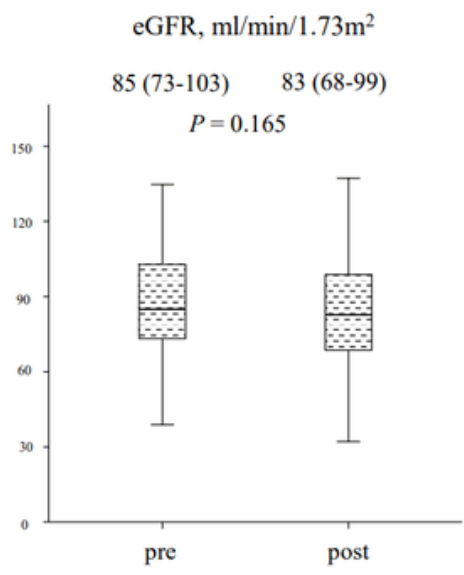

UACR, mg/gCre

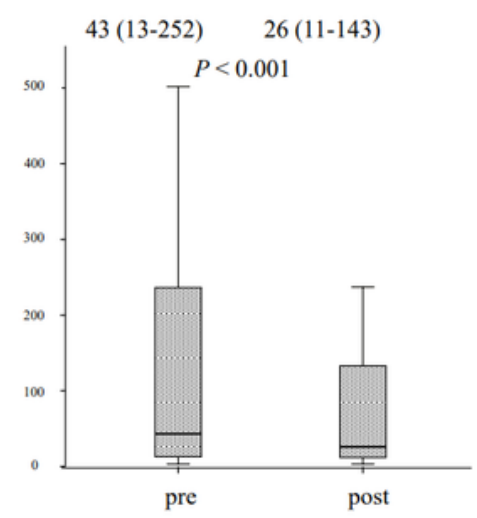

eGFR, $\mathrm{ml} / \mathrm{min} / 1.73 \mathrm{~m}^{2}$

UACR, mg/gCre
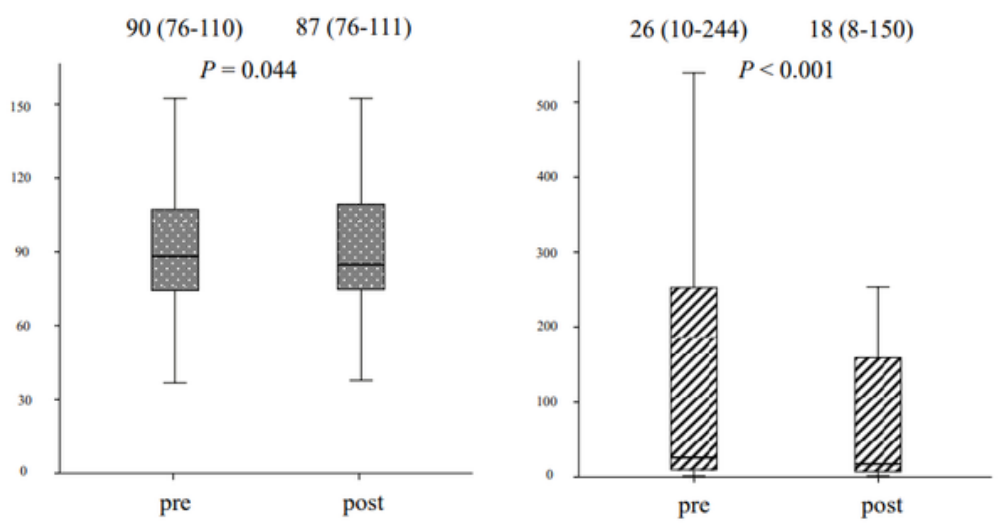

eGFR, $\mathrm{ml} / \mathrm{min} / 1.73 \mathrm{~m}^{2}$

84 (71-113) $\quad 87$ (76-111)

UACR, $\mathrm{mg} / \mathrm{gCre}$
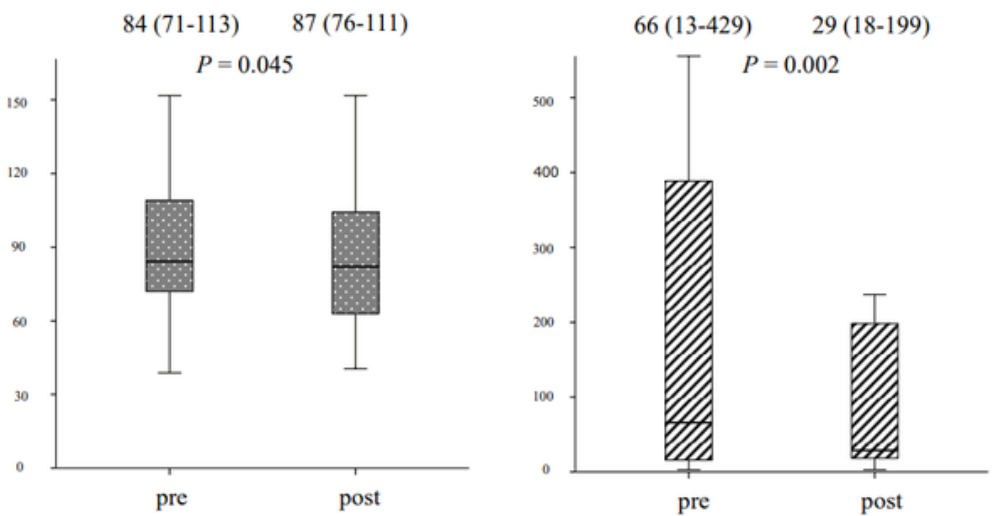

Figure 2

Changes in estimated GFR and UACR in all subjects before and 3 months after administration of usual dose of SGLT-2 inhibitors. Values are shown as median and the inter-quartile range. GFR, glomerular filtration rate, UACR, urinary albumin-to-creatinine ratio. 2a-Changes in estimated GFR and UACR in subjects with taking ARB internally before and 3 months after administration of usual dose of SGLT-2 inhibitors. The number of subjects taking ARB was 28 . Values are shown as median and the inter-quartile 
range. ARB, Angiotensin II Receptor Blocker, GFR, glomerular filtration rate, UACR, urinary albumin-tocreatinine ratio. $2 b-$ Changes in estimated GFR and UACR in subjects without taking ARB internally before and 3 months after administration of usual dose of SGLT-2 inhibitors. The number of subjects taking ARB was 35. Values are shown as median and the inter-quartile range. ARB, Angiotensin II Receptor Blocker, GFR, glomerular filtration rate, UACR, urinary albumin-to-creatinine ratio.

\section{Supplementary Files}

This is a list of supplementary files associated with this preprint. Click to download.

- FiguresandTables.pdf

- FiguresandTables.pdf 